\title{
Economicidade das Entidades Integrantes do Sistema Brasileiro de Poupança e Empréstimo
}

\author{
Luís Eduardo Pinto Lima*
}

1. Taxa Passiva. 2. Taxa Ativa. 3. Apuração do Custo Fixo. 4. Ponto de Equilíbrio Anual. 5. Volume de Captação com Lucro. 6. Taxa Ativa de Aplicação em Função do Volume Global. 7. Conclusão.

O presente estudo tem por objetivo traçar algumas considerações de ordem econômica a respeito das entidades integrantes do Sistema Brasileiro de Poupança e Empréstimo, visando à determinação de seu ponto de equilíbrio, com relação aos seus meios de captação de recursos e as premissas de ordem operacional, estabelecidas por via legal ou mercadológica. Partimos, assim, de dados concretos referentes às letras imobiliárias (tipos $C$ e $D$ ), depósitos de poupança, bem como dos empréstimos em forma de capital-estímulo através do Banco Nacional da Habitação. Os instrumentos básicos de captação das entidades do SBPE são as letras imobiliárias e as cadernetas de poupança. As letras imobiliárias podem ser do tipo $C$ e do tipo $D$. As letras do tipo $C$, também chamadas de renda, são letras cujo prazo é de 3 anos no mínimo e que pagam trimestralmente os seus rendimentos: juros de $2 \%$ ( $8 \%$ base-ano) e correção monetária,

* Diretor da Emissor S.A. Crédito, Financiamento e Investimentos e Diretor-Gerente da Emissor S. A., de Crédito Imobiliário. Bacharel em Administração de Emprêsas em 1967, na Escola de Administração de Emprêsas de São Paulo, da Fundação Getúlio Vargas.

R. Adm. Emp., Rio de Janeiro, 10(2): 149-167, jul./set. 1970 
igual à variação havida nas ORTN (Obrigações Reajustáveis do Tesouro Nacional). As letras do tipo $D$, também chamadas de poupança, são letras cujo prazo é de 1 ano no mínimo e, como diz o próprio nome, pagam no final seus rendimentos: juros à base de $8 \%$ ao ano e a correção monetária igual à variação havida nas ORTN, no período. Apesar dos prazos referidos, as letras imobiliárias têm liquidez pràticamente imediata, inclusive prevista na legislação. As cadernetas de poupança possuem uma carência de 180 dias para se fazer jus aos rendimentos, 0 que não impede que sejam retiradas a qualquer momento. Os rendimentos são: juros de $1,5 \%$ ao trimestre $(6 \%$ base-ano) e correção monetária igual a das ORTN, ambos calculados sôbre o menor saldo diário do trimestre transcorrido. Tanto as letras imobiliárias como as cadernetas de poupança, têm vantagens advindas de incentivos fiscais, e são garantidas pelo BNH. Consideramos, também, as necessárias apurações a respeito do custo estrutural das emprêsas, determinando, assim, seu break even point. Evidentemente, analisaremos uma sociedade-padrão, a qual tem características que representam valôres quantificáveis ou não, obtidos em nossas pesquisas diretas ou então extraídos da Revista Bancária Brasileira.

\section{Taxa Passiva}

A taxa passiva é a composição do custo de captação de recursos. Este custo engloba três fatôres distintos:

a) Comissão de colocação (corretagem e distribuição);

b) Fundo de Garantia dos depósitos e letras imobiliárias (seguro do Banco Nacional da Habitação);

c) Juros.

A taxa passiva é variável conforme, e em que grau, tenha a entidade o seu exigível representado por letras imobiliárias, depósitos de poupança, e ou em forma de capital-estimulo. No caso da colocação de letras, consideramos as taxas de colocação máximas permitidas pela resolução $n^{\circ} 137$ do Banco Central, que são absolutamente realistas em têrmos de mercado. Situaremos tôdas estas hipóteses pormenorizadamente. Esse estudo 
joga com a variável tempo que, evidentemente, influi nas taxas efetivas. Se não vejamos:

\subsection{LETRA IMOBILIARIA TIPO C — VENDA AO PÚBLICO}

No caso da colocação de uma letra imobiliária do tipo $C$, no valor de, por exemplo, $\mathrm{Cr} \$ 1.000,00$, nas condições citadas, teríamos um custo anual de:

a) Comissão de colocação: $2,25 \%$ a.a. $=\mathrm{Cr} \$ 22,50$ (paga no ato); (Resolução 137 do Banco Central do Brasil);

b) Seguros do BNH: $0,125 \%$ a.t. $=\mathrm{Cr} \$ 1,25$ (pagos trimestralmente);

c) Juros $2 \%$ a.t. $=\mathrm{Cr} \$ 20,00$ (pagos trimestralmente).

Então:

$$
977,50=21,25 \cdot \frac{1-(1+i)^{-4}}{i}+\frac{1.000,00}{(1+i)^{4}}
$$

Equação essa que representa a igualdade dos capitais na mesma época $O$.

Resolvendo através do Binômio de Newton, temos:

$977,5 \cdot i \cdot(1+i)^{4}=21,25\left[1-(1+i)^{-4}\right](1+i)^{4}+1.000 i$

$977,5 \cdot i \cdot(1+i)^{4}=21,25\left[(1+i)^{4}-1\right]+1.000 i$

$977,5 \cdot i \cdot\left(1+4 i+6 i^{2}+4 i^{3} \ldots\right)=21,25 \cdot i\left(4+6 i+4 i^{2}+\right.$

$$
\left.+6 i^{3} \ldots\right)+1.000 i
$$

Cancelando-se $i$ e desprezando-se os têrmos de potência maiores do que 2 (por serem insignificantes), resta-nos a equação do $2^{\circ}$ grau:

$$
5.780 i^{2}+3.782,5 i-107,5=0
$$

Extraindo os valôres de $i$, temos 0,027283 para o valor positivo e desprezamos o valor para $i$ menor do que zero.

Portanto, a taxa passiva trimestral é de $2,7283 \%$.

E a taxa passiva anual será:

$$
\left(1+i_{a}\right)=\left(1+i_{i}\right)^{4}
$$


Então:

$$
\begin{aligned}
& i_{a}=\left(1+i_{\mathfrak{l}}\right)^{4}-1 \\
& i_{a}=(1+0,027283)^{4}-1 \\
& \underline{i_{a} \cong 11,37 \%}
\end{aligned}
$$

Obs.: Não foram feitos os cálculos para prazos superiores a um ano, visto que o custo de corretagem teria renovação nesses mesmos períodos.

\subsection{LETRA IMOBILIÁRIA TIPO C - CAPITAL-ESTÍMULO - BNH}

Os custos normais de uma letra imobiliária do tipo $C$ colocada ao BNH, em forma de capital-estímulo, diferem, sobremaneira, daquelas em poder do público. Normalmente, essas letras têm o prazo de vencimento que oscila entre 4 e 10 anos. Para simplificação de cálculos, os quais são perfeitamente dispensáveis, admitimos um prazo médio de 7 anos, ou 28 trimestres.

Logo, por exemplo, uma letra no valor de $\operatorname{Cr} \$ 1.000,00$ custaria, efetivamente:

a) Taxa de administração, serviços técnicos e publicidade: $2,50 \%=\mathrm{Cr} \$ 25,00$ (pagos no ato);

b) Juros: $2,00 \%$ a.t. $=\mathrm{Cr} \$ 20,00$ (pagos trimestralmente);

c) Seguros do BNH: $0,125 \%$ a.t. $=\mathrm{Cr} \$ 1,25$ (pagos trimestralmente).

Então:

$$
975,00=21,25 \frac{1-(1+i)^{-28}}{i}+\frac{1.000,00}{(1+i)^{28}}
$$

Pelo mesmo processo de resolução, utilizado no item 1.1., a igualdade se verifica quando: $i \cong 2,356 \%$ a.t.

Logo, a taxa equivalente anual será:

$$
\underline{i_{a}=9,76 \%}
$$

\subsection{LETRA IMOBILIÁRIA TIPO D}

No caso da colocação de uma letra imobiliária do tipo $D$, no valor, também, de $\mathrm{Cr} \$ 1.000,00$, nas condições citadas, teríamos um custo anual de: 
a) Comissão de colocação: $2,25 \%$ a.a. $=\mathrm{Cr} \$ 22,50$ (paga no ato);

b) Seguros do $\mathrm{BNH}$ : 0,125\% a.t. $=\mathrm{Cr} \$ 1,25$ (pagos trimestralmente);

c) Juros: $8,00 \%$ a.a. $=\operatorname{Cr} \$ 80,00$ (pagos no fim do período). Então:

$$
977,50=1,25 \frac{1-(1+i)^{-4}}{i}+\frac{1.080,00}{(1+i)^{4}}
$$

Também pelo mesmo processo de resolução, utilizado no item 1.1., a igualdade se verifica quando: $1 \cong 2,648 \%$.

Logo, a taxa equivalente anual será:

$$
\underline{i_{\alpha}} \cong 11,02 \%
$$

\subsection{CADERNETA DE POUPANÇA}

Nesse item, fazemos considerações de custo, de um ponto de vista acadêmico, não sugerindo soluções diretas para a arrecadação das contas de poupança. As entidades, com êsses gabaritos, poderão, isso sim, ter mais facilidade em quantificar soluções intermediárias, ou mesmo diversas.

A caderneta de poupança poderá ser colocada, pelas entidades do Sistema Brasileiro de Poupança e Empréstimo, através da rêde de corretores, com um custo de colocação da ordem de $2 \%$ a.a.; ou, de outra forma, poderia montar uma série de lojas,

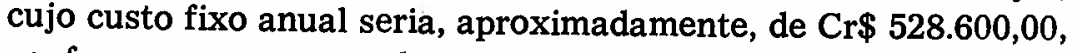
conforme veremos em demonstração logo a seguir.

Consideramos que, para a captação dêsse tipo funcionar a regime, seria necessário que as entidades trabalhassem com cêrca de 10 lojas, no mínimo.

A experiência nos ensina que a área média ocupada por funcionário é de $6 \mathrm{~m}^{2}$. Sendo assim, com 4 funcionários por loja, o mínimo que conceituamos como ideal, teriamos lojas de aproximadamente $24 \mathrm{~m}^{2}$. Para a loja ser interessante, deve localizarse em pontos que, segundo nossas pesquisas, a locação mensal custe, em média, $\operatorname{Cr} \$ 20,00$ por metro quadrado. 
Portanto, 10 lojas nesses caracteres perfazem um custo anual locativo de $\operatorname{Cr} \$ 57.600,00$.

Com relação aos 4 funcionários citados, teríamos:

1 Gerente
1 Relações Públicas
1 Caixa
1 Contínuo

Leis Sociais $(70 \%)$
Cr $\$ 1.000,00$ ao mês; 600,00 ao mês; 500,00 ao mês; 150,00 ao mês;

Cr\$ 2.250,00 ao mês; $1.575,00$ ao mês;

Cr\$ 3.825,00 ao mês:

Em um ano, nas 10 lojas, supondo a mesma distribuição, teremos o custo de $\operatorname{Cr} \$ 459.000,00$.

E, finalmente, para cálculo das depreciações, apuramos o custo aproximado atual que importa uma loja para essa função. Aproximadamente $\mathrm{Cr} \$ 12.000,00$. Para o índice depreciativo de $10 \%$ a.a. temos, para as 10 lojas, o custo de $\mathrm{Cr} \$ 12.000,00$.

Concluindo, podemos dizer que, somando as três espécies de custos, teríamos um custo fixo anual, para manter a série de lojas, de Cr\$528.600,00.

Paralelamente, analisando da mesma forma dos itens anteriores os custos variáveis que envolvem a caderneta de poupança (juros e seguros trimestrais de $1,5 \%$ e $\mathbf{0 , 1 2 5 \%}$, respectivamente) teremos:

a) Pagando comissão de $2,00 \%$ (na rêde de corretores), custo anual de $8,95 \%$.

b) Sem comissão (c/a rêde de lojas), custo anual de $6,66 \%$.

Evidentemente, apesar de oferecer um custo variável maior, a primeira hipótese, isto é, utilizando a rêde de corretores, é muito mais favorável, pôsto que não envolve compromissos de custo fixo, haja ou não captação. Isso, ainda, sem considerarmos o volume de trabalho administrativo central que causaria uma série de lojas, bem como o leverage negativo decorrente da imobilização do capital para a implantação das mesmas. Con- 
siderações quantificáveis daremos logo a seguir, nos estudos de ponto de equilíbrio.

\subsection{PROJEÇÃO DA ATUAL DISTRIBUIÇAOO}

$\mathrm{Na}$ prática, as entidades não mantêm o seu exigivel representado por uma fonte única de recursos, havendo diversificação das mesmas.

Assim sendo, na sua taxa passiva, deverá estar ponderada essa diversificação. A distribuição, que fornecemos a seguir, reflete, com bastante aproximação, a situação real.

Letras imobiliárias (tipos $C$ e $D$ ) - Público $=59,6 \%$

Cadernetas de poupança (sem comissão e custo fixo adicional) $=6,4 \%$

Empréstimos do Banco Nacional da Habi-

tação (letra imobiliária $\times$ capital estímulo) $=34,0 \%$

Portanto, ponderando êsses fatôres, encontraremos uma taxa passiva anual de $10,42 \%$.

\subsection{RESUMO DAS TAXAS PASSIVAS}

\begin{tabular}{lr}
\hline \multicolumn{1}{c}{ Hipóteses } & Taxa \\
\hline Letra Imobiliária Tipo C - Público & \\
Letra Imobiliária Tipo C - BNH & $11,37 \%$ \\
Letra Imobiliária Tipo D & $9,76 \%$ \\
Caderneta de Poupanca (com comissão) & $\mathbf{1 1 , 0 2 \%}$ \\
Caderneta de Poupanca (sem comissão) & $\mathbf{8 , 9 5 \%}$ \\
Projetando a atual distribuição & $6,66 \%$ \\
\hline
\end{tabular}

* Obs.: Apenas o custo variável. Há que se considerar o acréscimo no custo fixo (lojas), de $\operatorname{Cr} \$ 528.600,00$ ou aproximadamente $60 \%$.

\section{Taxa Ativa}

A taxa média ativa permitida pelo Banco Nacional da Habitação é de $13 \%$ a.a., que poderá, contudo, ser aumentada pela compra de segundas hipotecas, onde a taxa é livre. Não estamos, nesta última proposição, afirmando ser êsse o objetivo das entidades. Por outro lado, também, na consideração de fatôres 
implìcitamente ligados à dinâmica operacional, tomaremos como taxa ativa de aplicação, $14 \%$. A razão dêsse acréscimo de $1 \%$ se deve a dois fatôres:

\section{a) Com relação aos Planos Aquisição e Desconto:}

- Reaplicação dos retornos nas mesmas condições;

b) Com relação aos Planos Construção Civil e Individual:

- Reaplicação dos próprios juros e da taxa de abertura de crédito.

Quanto à forma de se operar, no que refere às taxas de abertura de crédito ou juros a serem cobrados para obter-se uma taxa média efetiva predeterminada, vejamos o seguinte: a taxa média efetiva é composta de três fatôres distintos, que se interrelacionam: taxa de juros, taxa de abertura de crédito (deságio) e prazo da operação.

Para os planos aquisição e desconto, utilizamos, de uma forma bastante elementar, a Tabela Taxa Efetiva das Operaçōes Financeiras do Banco Nacional da Habitação. Para obtermos valôres não constantes na Tabela, utilizamos a mesma fórmula que serve de elaboração para a referida tabela.

$$
d=1-\frac{{ }^{a} \bar{n} i^{-1}}{{ }^{a} \bar{n} \mid e^{-1}}
$$

onde:

$\mathrm{d}=$ taxa de abertura de crédito

$\mathrm{i}=$ taxa de juros

$\mathrm{e}=$ taxa média efetiva

$\left.{ }^{a} \overline{\mathrm{n}}\right|^{-1} i, \mathrm{e}=$ (Fator Tabela Price)

$\mathbf{n}=$ período.

Para melhor entendimento, exemplificamos:

Financiamento em 10 anos; taxa de juros $10 \%$ e taxa efetiva $11 \%$.

Então, obtemos a taxa de abertura de crédito:

$$
d=1-\frac{0,013215}{0,013775}=1-0,9593=0,0407 \text { ou } 4,07 \%
$$


$0^{a} \bar{n} \mid i, e^{-1} \quad$ (Fator Tabela Price) é dado por tabelas de matemática financeira. De qualquer forma, é fácil calcular pelo inverso da formula:

$$
a \bar{n} \mid i=\frac{1-(1+i)^{-n}}{i} \text { ou } a \bar{n} \mid i=\frac{1-\frac{1}{(1+i)^{n}}}{i}
$$

Para os planos construção civil ou individual, podemos, de posse do cronograma financeiro da obra, determinar o valor atual dos saques a serem liberados ao longo do período, aplicando-se o fator valor presente. Em outras palavras, seria como se o financiamento retirasse todo o empréstimo, por um valor menor, na época inicial.

Esse valor é capitalizado pelo prazo total da operação (inclusive carência) à taxa de juros $(10 \%)$ e à taxa efetiva ( $15 \%$ construção civil ou $13 \%$ construção individual). A diferença dos montantes dessa capitalização, corresponde, em valor presente, à taxa de abertura de crédito.

\section{Apuração do Custo Fixo}

Para a apuração do custo fixo médio anual, ou seja, a somatória dos gastos administrativos, foram analisadas, aproximadamente, 16 entidades. As informações para essa análise foram obtidas das fontes já mencionadas no início do estudo. Apuramos como média, um custo fixo anual bem aproximado de ...... $\mathrm{Cr} \$ 885.000,00$.

Como nem tôdas as entidades distinguiram os gastos de publicidade e propaganda, estimamos êstes gastos, com a ajuda daquelas que forneceram êsses elementos, em $15 \%$ do total das despesas. Assim sendo, o custo estimado, incluindo publicidade, se eleva para Cr\$1.019.000,00.

\section{Ponto de Equilibrio Anual}

De uma forma geral, para as hipóteses formuladas, bem como para a situação que mais se aproxima da realidade; para encontrarmos o ponto de equilíbrio adotaremos a liquidez média das entidades no valor de $9 \%$ (a liquidez mínima exigida pelo Banco 
Nacional da Habitação é de $7 \%$ ). Esse valor de $9 \%$ é obtido da seguinte forma: $4 \%$ parte do volume de recursos e $5 \%$ como se o capital estivesse parado em disponibilidade (não consideramos a sua imobilização por ser valor pequeno e estar, de qualquer forma, contido nesse índice considerado conservador). Dessa forma, o fator de aplicação ou aproveitamento usado, é de $96 \%$.

Tôdas as hipóteses a seguir consideradas para a determinação do break even point, à exceção da última, são bastante teóricas, sendo, contudo, interessante notar, para as posteriores conclusões e orientações, o quanto oscila o resultado final em virtude de uma simples alteração em um dos fatôres componentes da equação de equilíbrio, no caso a distribuição de tipos dos recursos captados.

4.1. PRIMEIRA HIPOTESE: SOCIEDADE OPERANDO APENAS COM LETRA IMOBILIARIA TIPO $\mathrm{C}$ - PÚBLICO

Então temos:

Taxa Passiva $=11,37 \%$

Taxa Ativa $=14,00 \%$

Custo Fixo $=885.000,00$

Pela equação que traduz o ponto de equilíbrio, onde:

receita $=$ despesa, temos:

Receita $=V \cdot 0,14 \cdot 0,96$

Despesa $=V \cdot \mathbf{0}, 1137+885.000$

onde: $\mathrm{V}=$ volume de letras.

Portanto:

$\mathrm{V} \cdot \mathbf{0 , 1 4} \cdot \mathbf{0 , 9 6}=\mathrm{V} \cdot \mathbf{0 , 1 1 3 7}+\mathbf{8 8 5 . 0 0 0}$

$\mathrm{V} \cdot 0,1344-\mathrm{V} \cdot 0,1137=885.000$

$\mathrm{V} \cdot \mathbf{0 , 0 2 0 7}=\mathbf{8 8 5 . 0 0 0}$

Então:

$\mathrm{V}=42.753 .600,00$ ou aproximadamente $\mathrm{Cr} \$ \mathbf{4 2 . 8 0 0 . 0 0 0 , 0 0}$ 
4.2. SEGUNDA HIPOTESE: SOCIEDADE OPERANDO APENAS COM LETRA IMOBILIARIA TIPO C - CAPITAL-ESTIMULO - BNH Então temos:

Taxa Passiva $=9,76 \%$

Taxa Ativa $=14,00 \%$

Custo Fixo $=885.000,00$

Pela equação que traduz o ponto de equilíbrio, onde:

receita $=$ despesa, temos:

Receita $=\mathrm{V} \cdot 0,14 \cdot 0,96$

Despesa $=V \cdot 0,0976+885.000$

onde: $\mathrm{V}=$ volume de letras.

Portanto:

$\mathrm{V} \cdot 0,14 \cdot 0,96=\mathrm{V} \cdot 0,0976+885.000$

$\mathrm{V} \cdot 0,1344-\mathrm{V} \cdot 0,0976=885.000$

$\mathrm{V} \cdot 0,0368=885.000$.

Então:

$\mathrm{V}=24.048 .913,00$ ou aproximadamente $\mathbf{C r} \$ \mathbf{2 4 . 0 0 0 . 0 0 0 , 0 0}$.

4.3. TERCEIRA HIPOTESE: SOCIEDADE OPERANDO APENAS COM LETRA IMOBILIARIA TIPO D

Então temos:

Taxa Passiva $=11,02 \%$

Taxa Ativa $=14,00 \%$

Custo Fixo $=885.000,00$

Pela equação que traduz o ponto de equilíbrio, onde:

receita $=$ despesa, temos:

Receita $=V \cdot 0,14 \cdot 0,96$

Despesa $=V \cdot 0,1102+885,000$

onde: $\mathrm{V}=$ volume de letras. 
Portanto:

$\mathrm{V} \cdot \mathbf{0 , 1 4} \cdot 0,96=\mathrm{V} \cdot 0,1102+885.000$

$\mathrm{V} \cdot 0,1344-\mathrm{V} \cdot 0,1102=885.00$

$V \cdot 0,0242=885.000$

Então:

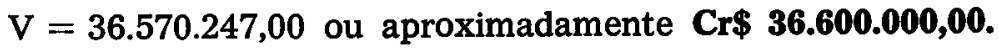

4.4. QUARTA HIPÓTESE: SOCIEDADE OPERANDO APENAS COM RECURSOS CAPTADOS ATRAVÉS DAS CADERNETAS DE POUPANÇA - VIA REDE DE CORRETORES

Então temos:

Taxa Passiva $=8,95 \%$

Taxa Ativa $=14,00 \%$

Custo Fixo $=885.000,00$

Pela equação que traduz o ponto de equilíbrio, onde:

receita $=$ despesa, temos:

Receita $=V \cdot 0,14 \cdot 0,96$

Despesa $=V \cdot 0,0895+885.000$

onde: $\mathrm{V}=$ volume de captação

Portanto:

$\mathrm{V} \cdot \mathbf{0 , 1 4} \cdot \mathbf{0 , 9 6}=\mathrm{V} \cdot 0,0895+885.000$

$V \cdot 0,1344-V \cdot 0,0895=885.000$

$\mathrm{V} \cdot 0,0449=885.000$

Então:

$\mathrm{V}=19.710 .467,00$ ou aproximadamente $\mathrm{Cr} \$ 19.700 .000,00$.

4.5. QUINTA HIPOTESE: SOCIEDADE OPERANDO APENAS COM RECURSOS CAPTADOS ATRAVES DAS CADERNETAS DE POUPANÇA - VIA REDE DE LOJAS

Então, temos:

Taxa Passiva $=6,66 \%$

Taxa Ativa $=14,00 \%$ 

Custo Fixo $=885.000,00+528.600,00=$$$
=1.413 .600,00 \text {. }
$$

Pela equação que traduz o ponto de equilíbrio, onde:

receita $=$ despesa, temos:

Receita $=V \cdot 0,14 \cdot 0,96$

Despesa $=V \cdot 0,0666+1.413 .600$

Onde: $\mathrm{V}=$ volume de captação

Portanto:

$\mathrm{V} \cdot 0,14 \cdot 0,96=\mathrm{V} \cdot 0,0666+1.413 .600$

$\mathrm{V} \cdot 0,1344-\mathrm{V} \cdot 0,0666=1.413 .600$

$v \cdot 0,0678=1.413 .600$.

Então:

$V=20.849 .550,00$ ou aproximadamente $\operatorname{Cr} \$ \mathbf{2 0 . 8 0 0 . 0 0 0 , 0 0}$.

\subsection{SEXTA HIPOTESE: PROJEÇÃO DA ATUAL DISTRIBUIÇĀO}

Como sexta e última hipótese, concluiremos admitindo uma distribuição projetada da conjuntura atual, ou seja, utilizaremos, assim, os mesmos percentuais de distribuição das formas ide recursos, com os quais a maioria das emprêsas vem operando atualmente e que, a curto prazo, não tendem a sofrer modificações radicais. Dessa forma, então, obteremos o break even point da entidade-padrão.

Admitindo-se, então, a mesma composição dos recursos, já citada, ou seja:

$59,6 \%$ - Letras Imobiliárias tipos $C$ e $D$ - Público

$6,4 \%$ - Cadernetas de Poupança

$34,0 \%$ - Capital-Estímulo - BNH

Teremos a taxa passiva proporcional de $10,72 \%$.

Então, temos:

Taxa Passiva $=10,42 \%$

Taxa Ativa $=14,00 \%$

Custo Fixo $=885.000,00$ 
Pela equação que traduz o ponto de equilíbrio, onde:

Receita $=$ Despesa, temos:

Receita $=\mathrm{V} \cdot 0,14 \cdot 0,96$

Despesa $=V \cdot 0,1042+885.000$

onde: $\mathrm{V}=$ volume global de recursos.

Portanto:

$V \cdot 0,14 \cdot 0,96=V \cdot 0,1042+885.000$

$\mathrm{V} \cdot \mathbf{0 , 1 3 4 4 - \mathrm { V } \cdot 0 , 1 0 4 2 = 8 8 5 . 0 0 0}$

$\mathrm{V} \cdot 0,0302=885.000$.

Então:

$\mathrm{V}=29.304 .635,00$ ou aproximadamente $\operatorname{Cr} \$ 29.300 .000,00$.

Concluindo, podemos afirmar que, o ponto de equilíbrio, ou seja, aquêle onde não há lucro nem prejuízo, a sociedade, no nosso caso-padrão, deverá operar com um volume de $\mathrm{Cr} \$ 29.300 .000,00$.

Este é o ponto mínimo, dentro dos pressupostos assumidos, para que a organização alcance equivalência entre receita e despesa. Entretanto, a abordagem destas hipóteses demonstrou, e indiretamente deixou claro a gama de variações e alternativas que poderão ocorrer no resultado final, conforme essa ou aquela filosofia da alta administração. A seguir, apresentamos o gráfico do break even point para a sexta e última hipótese:

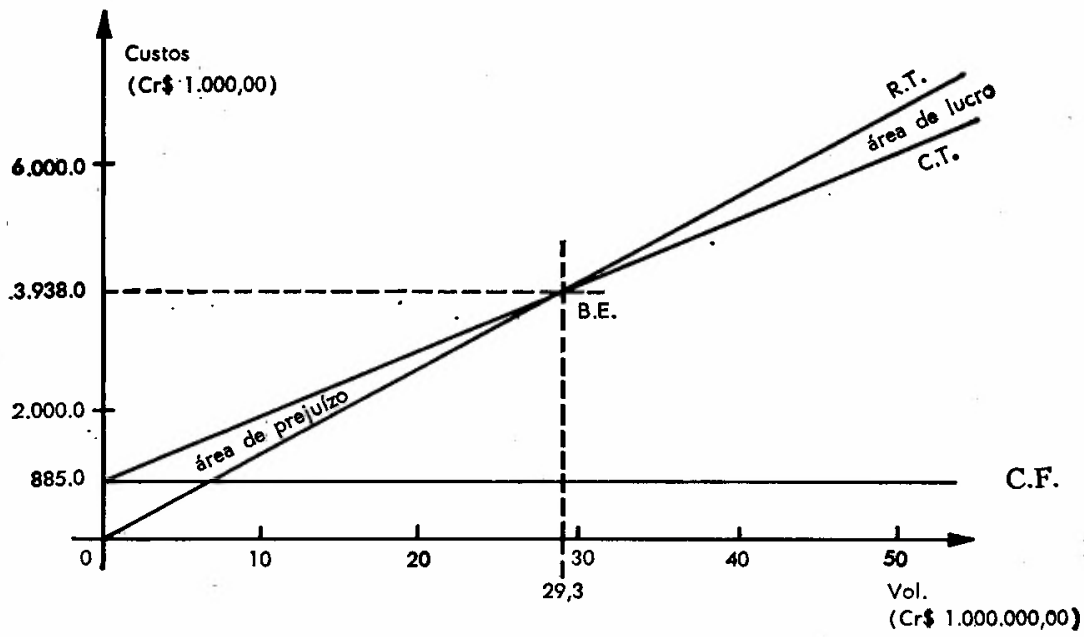


1. Apenas com Letra Imobiliaria Tipo C Público

$42.800 .000,00$

2.* Apenas com Letra Imobiliária Tipo $C$ BNH

$24.000 .000,00$

3.* Apenas com Letra Imobiliária Tipo $D$

36. $600.000,00$

4. Apenas com Caderneta de Poupanca (Corretores)

19.700.000,00

5." Apenas com Caderneta de Poupanca (Lojas)

$20.800 .000,00$

6." Projetando a atual distribuição

$29.300 .000,00$

Obs.: Isso demonstra, em particular, a grande vantagem de se dar mais enfase para os dep6sitos de poupança, o que vem de encontro à filosofia do Banco Nacional da Habitação.

\section{Volume de Captação com Lucro}

A meta de lucro tida como média podemos dizer que está por volta dos Cr\$300.000,00. Percentualmente representa $20 \%$ do capital médio das entidades ( $\mathrm{Cr} \$ 1.500 .000,00)$. Esse lucro é real e considerado ótimo para uma economia estabilizada. Nesse estudo não estamos incluindo os aspectos decorrentes da inflação, sendo, pois, conservador em face da mecânica operacional referente à correção monetária.

Para essa análise, projetamos a atual distribuição dos meios de captação de recursos. Portanto, pela mesma equação já formulada, agora acrescida da meta de lucro na parte passiva, consideramos duas hipóteses:

Sociedade trabalhando sem propaganda

Sociedade trabalhando com propaganda

\subsection{EMPRESA TRABALHANDO SEM PROPAGANDA}

Receita = Despesa

$\mathrm{V} \cdot 0,14 \cdot 0,96=\mathrm{V} \cdot 0,1042+885.000+300.000$

$\mathrm{V} \cdot 0,1344-\mathrm{V} \cdot 0,1042=1.185 .000$

$\mathrm{V} \cdot \theta, 0302=1.185 .000$

Portanto:

$\mathrm{V}=39.238 .410,00$ ou aproximadamente $\mathrm{Cr} \mathbf{3 9 . 2 0 0 . 0 0 0 , 0 0}$ 


\subsection{EMPRESA TRABALHANDO COM PROPAGANDA}

Receita $=$ Despesa

$\mathrm{V} \cdot 0,14 \cdot 0,96=\mathrm{V} \cdot 0,1042+1.19 .+3$.

$\mathrm{V} \cdot, 1344-\mathrm{V} \cdot, 142=1.319$.

$\mathrm{V} \cdot 0,0302=\mathrm{V} \cdot 1.319$.

Portanto:

$\mathrm{V}=43.675 .496,00$ ou aproximadamente $\mathrm{Cr} \$ \mathbf{4 3 . 7 0 0 . 0 0 0 , 0 0}$.

Então, remunerando em $20 \%$ o capital médio das sociedades dentro dos pressupostos assumidos, deverão operar com os volumes de:

Cr\$ 39.200.000,00 - operando sem propaganda;

Cr\$ 43.700.000,00 - operando com propaganda.

\section{Taxa Ativa de Aplicação em Função do Volume Global}

Poderemos concluir tedricamente, pelo que foi dito, que a taxa ativa de aplicação poderá declinar em função do aumento do volume global. Isso permitirá às sociedades, mantendo a rentabilidade, operarem com taxas até menores do que as atuais, proporcionando, assim, melhores condiçóes de trabalho no mercado, além da maior adaptação às tendências da atual política econômico-financeira.

Se não, vejamos:

Pela nossa equação do ponto de equilíbrio, temos:

$\mathrm{V} \cdot 0,14 \cdot 0,96=\mathrm{V} \cdot 0,1042+885.000$

Se isolarmos a taxa ativa (no caso $14 \%$ ) colocando-a em função dos demais elementos da equação e estipularmos a $V$ (volume de recursos) valôres crescentes, observaremos, conforme mostra o gráfico logo a seguir, o perfeito declínio da mesma. E bem possivel que, com o aumento de volume global, o custo fixo tende a aumentar; entretanto, serão em proporções bem insignificantes, que não alterarão a tendência projetada: 
Então:

$$
\mathrm{TA}=\frac{\mathrm{V} \cdot 0,1042+885.000}{\mathrm{~V} \cdot 0,96}
$$

Para:

$$
\begin{aligned}
& \mathrm{V}=10.000 .000,00 \mathrm{TA}=20,07 \\
& \mathrm{~V}=20.000 .000,00 \mathrm{TA}=15,46 \\
& \mathrm{~V}=29.300 .000,00 \mathrm{TA}=14,00 \\
& \mathrm{~V}=30.000 .000,00 \mathrm{TA}=13,93 \\
& \mathrm{~V}=40.000 .000,00 \mathrm{TA}=13,16 \\
& \mathrm{~V}=50.000 .000,00 \mathrm{TA}=12,70 \\
& \mathrm{~V}=60.000 .000,00 \mathrm{TA}=12,39 \\
& \mathrm{~V}=70.000 .000,00 \mathrm{TA}=12,17 \\
& \mathrm{~V}=80.000 .000,00 \mathrm{TA}=12,01 \\
& \mathrm{~V}=90.000 .000,00 \mathrm{TA}=11,88 \\
& \mathrm{~V}=100.000 .000,00 \mathrm{TA}=11,78
\end{aligned}
$$

TAXA ATIVA EM FUNIÇÃO DO VOLUME GLOBAL

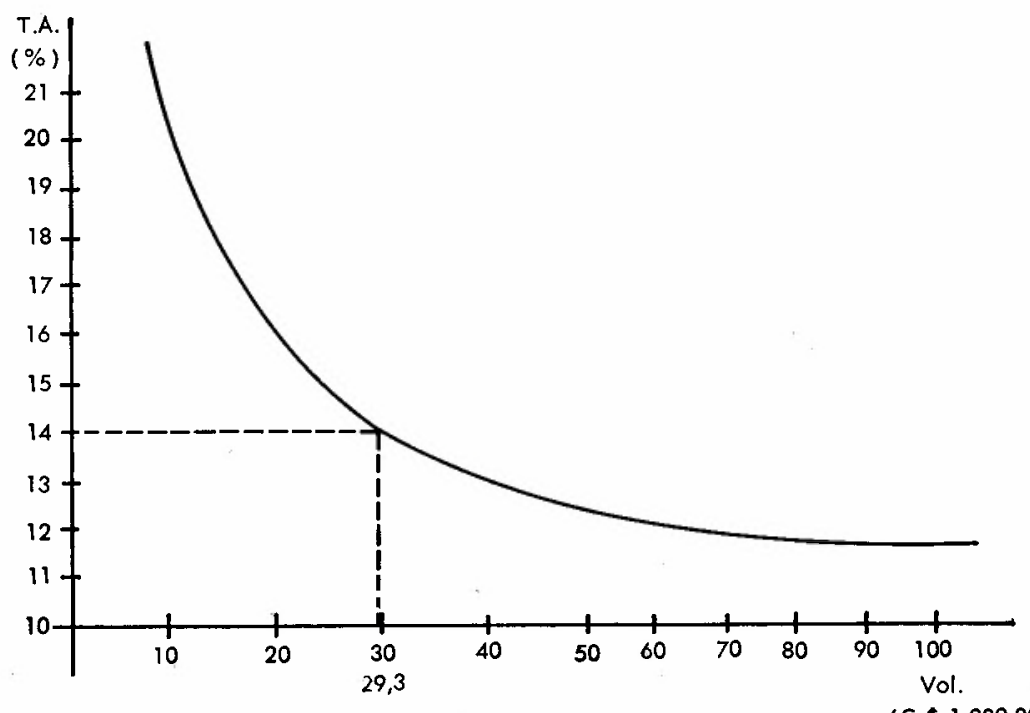

(Cr $\$ 1.000 .000,00)$ 


\section{Conclusão}

O presente estudo procurou estabelecer suas premissas de forma genérica, baseando-se na média dos valôres representativos das entidades do Sistema.

Assim sendo, as conclusões são válidas numa análise estatística que tem em contrapartida a variação de cada caso específico. Portanto, cada entidade, conhecendo com maior profundidade suas variáveis, poderá aplicá-las, extrair as próprias conclusões e traçar, com maior precisão, suas metas básicas.

O componente custo de captação deve receber, por parte das entidades, cuidado especial no sentido de uma minimização em face do seu pêso de incidência nos custos totais. Nessa alternativa, se vai de encontro à filosofia do Banco Nacional da Habitação, ao se observar que a captação de recursos através das cadernetas de poupança oferece êsse custo, nos menores valôres, embora tendo que se ponderar com muito cuidado a decisão de modus faciendi; a rêde de lojas, por exemplo, representa um compromisso alto e permanente em têrmos de custo.

Já com relação aos volumes de recursos que proporcionam o ponto de equilíbrio, podemos dizer que há situações diversas para entidades semelhantes. Não se pode ater às conclusões tiradas de uma análise feita com valôres médios, pois há bastante variação dos custos estruturais, da mecânica de reaplicação dos vários planos, e até mesmo do coeficiente de liquidez de cada entidade em particular. Entretanto, em tese, pode-se observar que algumas entidades estão além e muitas estão aquém do break even point.

Quanto à tendência do sistema, ou de cada entidade em particular, as perspectivas não são muito animadoras, ao se projetar a situação atual; poderão sofrer transformações radicais que dependerão do trabalho de cada uma delas e do apoio do Banco Nacional da Habitação, em face dos altos valôres envolvidos, bem como, e principalmente, do aspecto social do Sistema.

Isso porque não parece muito viável o aumento do custo dos empréstimos, principalmente para o mutuário, ao estabelecermos comparação com o de outros países em estágio sócio-econô- 
mico semelhante ao nosso; mas se poderia ter maior contribuição do empresário da construção civil para o aumento da taxa média efetiva.

Seria recomendável, também, que tôdas as autoridades monetárias reunidas consolidassem a legislação vigente procurando incentivar, e tornar eficientes e definitivos, os mecanismos de empréstimos externos que seriam aplicados efetivamente numa atividade de alta alavancagem econômica para o desenvolvimento do nosso país.

Outra forma eficiente de se resolver o problema e consolidar definitivamente as entidades do Sistema Brasileiro de Poupança e Empréstimo, seria fazer das mesmas agentes do Banco Nacional da Habitação - no verdadeiro sentido da palavra contribuindo, através da intermediação em tôdas as operações do Banco e minorando a incidência do custo fixo de ambos, ao mesmo tempo em que se apura a qualidade daquelas operações pela grande eficiência demonstrada historicamente, quando trabalhando num objetivo comum, se consagra o binômio Govêrno-Iniciativa privada.

A nova CONJUNTURA ECONOMICA permanece tradicional. É ainda objetiva, precisa, imparcial e atualizada. Tudo como antes. Ficou, é claro, mais bonita, moderna, e seu formato é maior. Para facilitar as consultas e tentar, depois, o leitor a deixálla em cima da mesa, só para enfeitar.

Uma publicação da Fundação Getúlio Vargas. Procure nas bancas ou escreva para a Praia de Botafogo 188, Caixa Postal 21.120, ZC-05, Rio de Janeiro, GB. 